\title{
Animal experimentation: A look into ethics, welfare and alternative methods
}

\section{EXPERIMENTAÇÃO ANIMAL: UM OLHAR SOBRE ÉTICA, BEM-ESTAR E MÉTODOS ALTERNATIVOS}

\author{
Marcos Rassi Fernandes ${ }^{1 *}$, Aline Ribeiro Pedroso² \\ ${ }^{1} \mathrm{MD}$. PhD in Health Sciences, Department of Orthopedics and Traumatology, Faculty of Medicine, Universidade Federal de Goiás (FMUFG), Goiânia, GO, Brazil \\ ${ }^{2}$ MSc Student of the Graduate Program in Health Sciences, FMUFG, Goiânia, GO, Brazil \\ Study performed by the Graduate Program in Health Sciences, Faculty of Medicine, Universidade Federal de Goiás, Goiânia, GO, Brazil \\ *Correspondence: \\ Address: Av. Azaléias, Qd. 10 Lt. 20 \\ Aparecida de Goiânia, GO - Brazil \\ Postal code: $74935-187$ \\ marcosombro@ig.com.br
}

\section{INTRODUCTION}

Since the fifth century BC, there have been reports of scientific experiments involving animals, but their use has become more frequent since the nineteenth century. Animal welfare would then comprise only stress reduction, animal suffering not being taken into account for many years. ${ }^{1}$ In 1824 , the first animal protection society, the Society for the Preservation of Cruelty to Animals, was established in England to promote animal comfort, thereby helping to prevent cases of cruelty. ${ }^{2}$

In 1959, Russell and Burch described the principle of the " 3 Rs" - Replace, Reduce, Refine - for research using animals. This principle recommended substituting conscious living vertebrates with phylogenetically more primitive life forms, such as the more degenerate metazoan microorganisms and endoparasites, or with computerized simulations. The reduction principle advised that research and procedures should be carried out with as few animals as possible, while the refinement principle suggested that the techniques used should decrease their pain and distress at all stages of the study.,3

In Brazil, Law No. 11,794/08, also known as the Arouca Law, regulates the use of animals in scientific experiments. Chapter IV of the Arouca Law describes the conditions for breeding and using these animals in teaching and scientific research, such as the use of sedation, analgesia or anesthesia in any experiment that may cause pain or distress. It also recommends performing euthanasia whenever the experiment is terminated or at any of its phases when there is intense suffering of the animal. ${ }^{4}$

The Arouca Law created Brazil's National Council for the Control of Animal Experimentation (Concea, Portuguese acronym for Conselho Nacional de Controle de Experimentação Animal), assigned to draw up the guide- lines and enforce compliance with them regarding the humane use of animals in scientific research. It also set up the Ethics Commissions on the Use of Animals (CEUAs, Portuguese acronym for Comissões de Ética no Uso de Animais) as an indispensable condition for the accreditation of teaching and research institutions that use animals in scientific experiments. ${ }^{4}$

The purpose of using animals in teaching is to illustrate or carry out procedures that are already known, unlike their use in research, which is aimed at contributing to developing new drugs or treatments, in addition to clarifying certain biological phenomena. ${ }^{5}$

Many advances in health sciences were possible thanks to scientific experiments conducted on animals. However, actions from non-governmental organizations (NGOs) towards protecting and preserving animals are still frequent. Some scientists argue that the predictive value of this type of research is often low and may lead to biased or imprecise results, which would result in unnecessary suffering to the animals and clinically irrelevant data. ${ }^{6}$

It can therefore be stated that the practice of animal experimentation is considered a widespread activity in the scientific environment. Nevertheless, it has provoked public reactions, and this practice has been intensely debated both in society and academic institutions. ${ }^{5,6}$

Our study was aimed at undertaking a narrative review on ethics and welfare in animal experimentation, as well as discussing alternative methods to its use.

\section{Choosing the animal model}

Meticulous research should be undertaken for project planning prior to initiating any experiment in order to avoid unnecessary use of living animals. ${ }^{3}$ There are reasons for their use in several studies, such as those investigating 
human diseases and in toxicity tests. In addition, animals are used as an asset to teaching health professionals and training their surgical skills. ${ }^{7}$

Investigators should know the particular traits of the species they intend to use, such as its physiology, developmental stages, reproductive characteristics, specific behaviors and nutritional needs. In practice, when actually conducting experiments, choosing the appropriate animal model is done based on how easy the husbandry practices and handling of the animal species are, rather than experimental design or animal biological relevance. ${ }^{8}$

Rodents, especially rats and mice, are among the most commonly used animals in scientific research. ${ }^{3}$ In the United States alone, 26 million mice and rats are used per year, which makes up to 96 to $98 \%$ of all animal testing. ${ }^{9}$

Rats are most appropriate for work involving shock, sepsis, obesity, peritonitis, cancer, gastric ulcers, intestinal operations, the mononuclear phagocytic system, spleen, wound healing and organ transplantations (Figure 1). Mice, in turn, are more suited to studying megacolon and burns, as well as shock, sepsis, obesity and cancer, as previously mentioned. ${ }^{3}$

Pigs are used in liver, stomach and transplantation studies (Figure 2), whereas rabbits are suited for studies on immunology, shock, inflammation, colitis, vascular operations and transplantations. Dogs fell into disuse, mainly due to the activity of NGOs engaged in protecting the species. However, their use was common in teaching surgical technique and studying shock, malabsorption, colitis, pancreatitis, hepatic and splenic operations, as well as transplantations. ${ }^{3}$

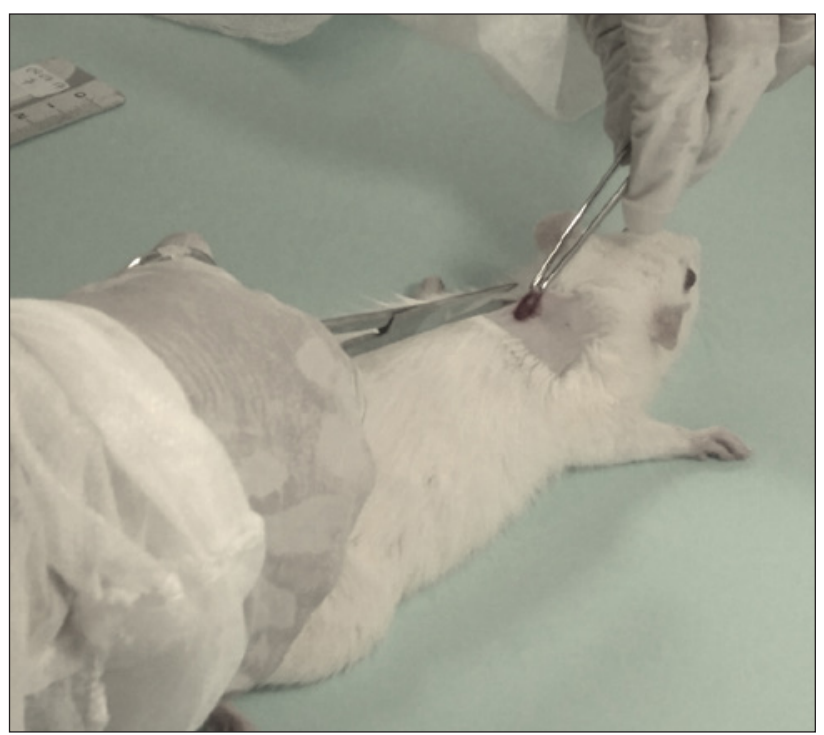

FIGURE 1 Healing test using rats as an animal model.

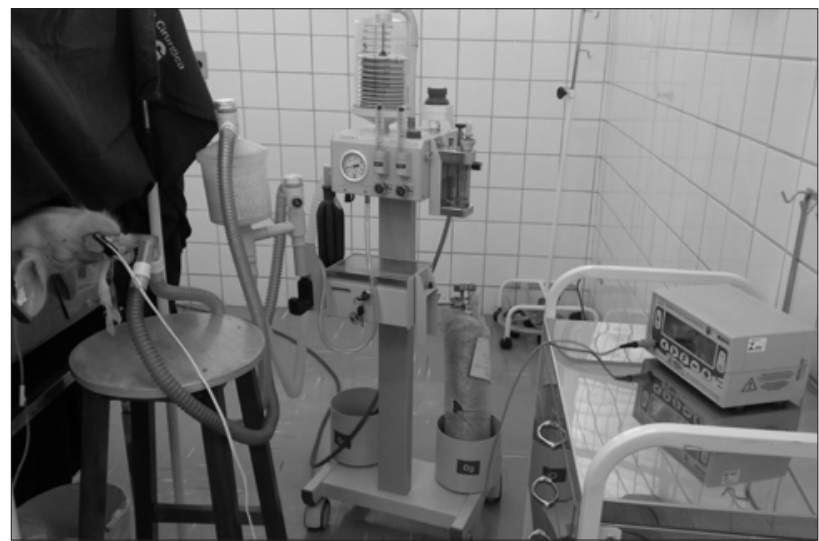

FIGURE 2 Operative technique using pigs as an animal model.

Thus, choosing an animal for laboratory use depends on the scientific research. There are some animals whose genetic lineage makes them prone to certain diseases, such as diabetes mellitus or high blood pressure, and therefore are ideal choices for testing drugs and/or procedures when studying such conditions. ${ }^{9}$

It is of utmost importance to know the microbiological standard of laboratory animals, given that it not only affects people, but can also influence the results of the experiments. Studies have been using an increasing number of specific pathogen-free (SPF) animals, that is, animals which are free of specific microorganisms and parasites. In order to obtain this type of sanitary status, it is essential that animals be husbanded and kept in settings that are protected by strict sanitary barriers and frequently monitored, since many rodent infections are subclinical. ${ }^{10}$

\section{HOUSING AND ENVIRONMENTAL ENRICHMENT}

Several aspects relative to the husbandry and housing of species are neglected. Group housing is important, but can give rise to aggression, hence causing pain, injury or death. Also, animals that are stressed or injured may compromise the scientific validity of the study. ${ }^{11}$

Investigators should be concerned about the circumstances in which animals are kept during the study, as well as familiarize themselves with the metabolism of the species kept in vivaria, which can be altered by factors such as confinement, stress, pain, lack of sunlight and more. ${ }^{8,12}$

Housing conditions not only affect the behavior of the animals but also interfere with the results of the experiments. Environmental enrichment and enhancement procedures help reduce stress and positively affect performance. ${ }^{6}$

Accordingly, knowledge of the specific behavior and physiology of the species is extremely important, so that 
experiments can be conducted while aiming at reducing pain, suffering and stress inside the enclosure, thereby promoting animal welfare and consequently increasing reliability of research data. ${ }^{13}$

Factors causing agony and distress in animals should be eliminated or controlled so that there is no interference in data collection and interpretation of results. The need for more animals, reduced reliability, increased variability in results and unnecessary use of lives all stem from impaired welfare. ${ }^{14}$

Animals should be kept in a safe and appropriate place in order to reduce experiment data variation arising from the environment. It is essential to keep variables such as temperature, humidity and airflow at levels that are appropriate for each species, since abrupt variations can cause stress, decreased resistance and greater susceptibility to infections. ${ }^{6,13}$

The space allocated to animals must permit free movement, sleep and contact with other animals of the same species. ${ }^{4}$ Rats and mice are very sociable animals and, therefore, should be housed in groups so that they can develop normal behavior. Laboratory cages are usually not suitable for the animals' behavioral needs. Hence, environmental enrichment is an important feature for them to express their natural behavior, which will affect their physiology and defense mechanisms. ${ }^{13}$

The enrichment features should satisfy their curiosity, provide them with fun activities, and allow for the fulfillment of their physiological and behavioral needs, such as building nests, exploring, gnawing and hiding. The use of igloos, cardboard/PVC tubes, cotton, paper towel, paper strips and disposable masks favors this objective. ${ }^{13}$

When a new animal is placed into the experiment's settings, they should go through a period of acclimatization (quarantine), as abrupt changes in their living conditions can elicit a pressure response, which, albeit temporary, can lead to distress. ${ }^{14}$

The environment to be used for animal housing must be constantly controlled by hygiene, disinfection, sanitation and sterilization processes. Several infectious agents found in vivaria, such as Sendai virus, Mycoplasma pulmonis and cestoda, are currently becoming increasingly rarer. However, the mouse hepatitis virus still remains a threat. ${ }^{10}$

\section{EUtHANASIA}

The term euthanasia is derived from Greek and means death without suffering. The Arouca Law (Article 14, Chapter IV, Paragraphs 1 and 2) states that an animal shall be subjected to euthanasia, in strict obedience to the requirements pertaining to each species, whenever the experiment is terminated or at any of its phases, where such a procedure is recommended, as well as whenever severe suffering occurs. If the animal should not be submitted to euthanasia, it may exceptionally leave the vivarium after intervention and be assigned to suitable persons or animal protection entities, duly legalized. ${ }^{4}$

Such a procedure is also indicated where the animal's welfare is irreversibly impaired and neither pain nor suffering can be controlled with analgesics or sedatives, or in those cases where the animal constitutes a threat to public health and a risk to the native fauna or to the environment. ${ }^{4,13,15}$

Euthanasia techniques should result in a rapid loss of consciousness followed by cardiac or respiratory arrest and definite impairment of brain function. It is important to handle the animal calmly and out of its enclosure, seeking to reduce distress, fear and anxiety. ${ }^{13}$

Prior to choosing the most appropriate method, one must take into consideration the animal species involved, the animal's age and physiological status, as well as the safety of the person euthanizing the animal. Every research project should contain the description of appropriate endpoints for the animal species and the procedures that will be used. ${ }^{13,15}$

There are both chemical and physical methods. The chemical methods available include injectable agents (barbiturates, propofol, potassium chloride); inhalable agents (carbon dioxide, nitrogen, argon); and anesthetics (halothane, isoflurane and sevoflurane). Physical ones comprise: compressed air gun (non-penetrating) and captive dart (penetrating); fire gun; decapitation; exsanguination; electrocution; maceration and cervical dislocation. ${ }^{15}$

The physical methods may be classified as either restricted or unacceptable. Therefore, it is important to search for the appropriate method for the species being used. After completion of the procedure, death should be confirmed before the animals' bodies are discarded. ${ }^{13-15}$

\section{Alternative methods}

The authorized use of animals in teaching activities raises very controversial issues, especially considering that it often involves invasive procedures. This is quite questionable in veterinary educational programs, where its ethical justification is to foster the progress of medical knowledge. ${ }^{16}$

Continuing medical education is increasingly changing, and the search for alternative methods in surgical training has been increasing, so as to avoid the overuse of animals, thereby reinforcing ethical principles and animal rights. Accordingly, educational institutions seek ways to teach surgical practice without compromising the quality of teaching. ${ }^{17}$ 
Some authors argue that animal experimentation, in addition to being detrimental to maintaining life and bodily integrity, avoiding pain and frustration, is also non-consensual, given that it is conducted on living beings that did not voluntarily agree to participate in the research. Despite technological advances in alternative methods, it is estimated that scientific research uses around 100 million animals every year worldwide. ${ }^{17-19}$

The use of animals in several studies remains unacceptable to some people, even to some researchers, due to their constant concern for animal welfare. However, some important pieces of information are not always externalized, such as animal care during the investigation and the role of the veterinarian in this process, ensuring that it is possible to balance scientific goals and animal welfare..$^{20,21}$

Most scientists and some members of the general public, nevertheless, agree that animal testing should be allowed where there are no other viable alternatives and provided that it is carried out under strict regulations. They believe it is useful to investigate disease mechanisms, validate new drugs, and to provide information on drug toxicity and interactions. ${ }^{7}$

The search for alternatives to animal experimentation, including its educational aspect, is experiencing intense evolution. These methods can be any given choice that can replace, reduce or refine the use of animals in biomedical research, testing or teaching. In the latter, animal experimentation can practically be replaced altogether without major impairment to learning. ${ }^{14,22}$

Some authors suggest the use of alternative techniques to animal testing, since they consider it an immoral and ineffective practice. These methods include in vitro tests (tissues and cells); the use of vegetables; non-invasive clinical studies in human volunteers; conducting studies with corpses instead; the use of lower organisms that are not classified as protected animals (shrimp and water flea larvae); physicochemical techniques; computer simulations; educational software; films; mathematical models; nanotechnology; and test dummies. ${ }^{22}$

Computer models run on specialized software and lower organisms (Figure 3 ) are the alternatives of choice for assessing the biological effectiveness of active drugs and molecular/genetic studies, ${ }^{23}$ respectively.

The use of porcine small intestine and pork belly skin has proved useful in teaching suturing, grafting and surgical knotting techniques. Still, the absence of bleeding restricts the training for hemostasis, which is thus a limiting factor..$^{17-19}$

The embryo of zebra fish (Danio-rerio) is considered a promising model for predicting toxicity in vertebrates, including humans. Its rapid development and transpar-

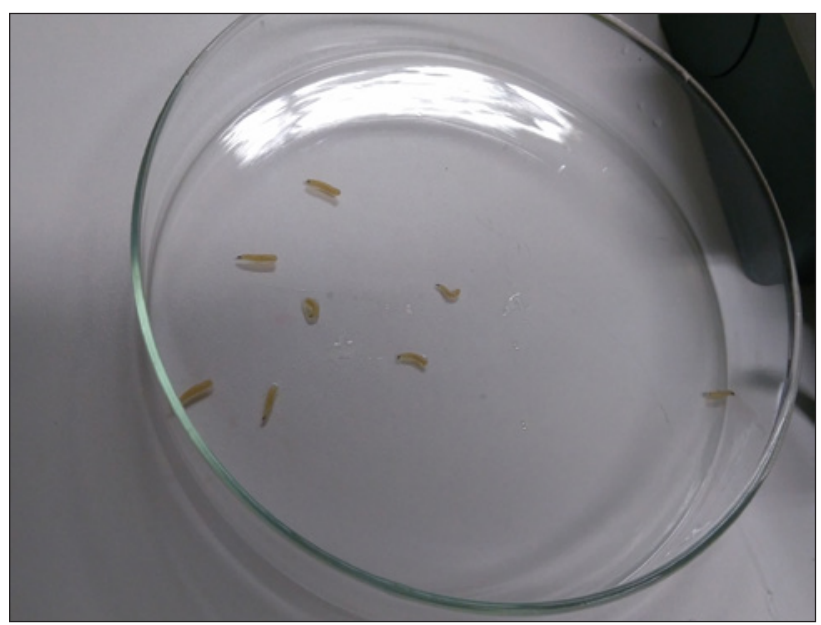

FIGURE 3 Use of inferior organisms as an alternative method to the use of vertebrate animals.

ency facilitate the evaluation of phenotypic effects, making it an effective model for the study of human diseases. ${ }^{24}$

Still, these alternative methods are at different stages of development and validation. This is a difficult and slow process, since it entails collaborative studies, which are in turn carried out in several places, and the analysis of interand intra-laboratory variations. ${ }^{22}$ They must undergo a series of evaluations, such as effectiveness, safety, toxicity, specificity, sensitivity and predictive value, before they can eventually be validated as alternative methods. ${ }^{8}$

Animal experimentation is still necessary for certain teaching and research practices, since there is still no sufficient technology to replace it altogether, ${ }^{2}$ but there has been a clear reduction in the number of studies involving animals over the last decades..$^{25}$

It is undeniable that in vivo animal experimentation has contributed to biological development and biomedical research, yet it is also associated with high production costs and strict ethical considerations. These limitations led to the development of a cost-effective ex vivo model that can effectively replace in vivo and in vitro models, thus contributing to animal welfare. ${ }^{26}$

Ex vivo models can be used to develop new therapies in which the disease can be identified at an earlier stage and treated with very advanced techniques. In dentistry, with the development of an ex vivo culture model, the investigation of inflammatory cell behavior and metabolism in different types of periodontal disease has become easy. ${ }^{23,26}$

\section{INVESTIGATORS' ETHICS}

The behavior of investigators and professionals who use animals in research has been changing based on the latest 
technology and science advances pertaining to laboratory animals. Currently, animal sensitivity is known to be similar to that of humans in regards to pain, memory, anguish and survival instinct. ${ }^{13}$ For this reason, it is the investigator's responsibility to monitor the animals operated on and recognize the signs of distress. There is no justification for the absence of analgesia in those animals undergoing invasive experimental surgery. ${ }^{27}$

Scientists are accountable for providing high-quality care to laboratory animals, such as easy access to water and a nutritious diet; prevention of and relief from pain, injury and disease; and appropriate housing for the species. ${ }^{28}$ Conducting research is not permitted in cases where the damage to the animal is greater than the gain in knowledge, since no scientific advance can be justified based on the suffering of other living beings. ${ }^{29}$ In addition to ensuring animal welfare, researchers must comply with the relevant legislation. Also, it is their responsibility to inquire about the subject. ${ }^{12}$

A clear legislation is mandatory, as well as conducting well-delineated research. ${ }^{2}$ Whenever animal experimentation is involved, it is necessary to invest time in appropriately designing the project in order to justify the ethical argument for carrying out the scientific investigation, especially when determining the number of animals needed for ensuring reproducible results. ${ }^{6}$

One should perform all experiments ethically and with a justification, not abusing one's human right over animals and in such a manner as to avoid their suffering. ${ }^{13}$ It is important that the use of animal testing be discussed especially in universities, from where future researchers will emerge. ${ }^{29}$

Scientists should make the best of their knowledge and experience so they can share with the general public the reasons why animal studies are important for scientific breakthroughs. All institutions engaged in animal research also have a moral obligation to play a more active role than they are currently doing in fostering education and maintaining a dialog with the general public. They should not only promote the evidence, but also share how they conduct their research and provide care to the animals involved. ${ }^{7,9,12}$

\section{Final CONSIDERATIONS}

It is evident that the use of animals in both research and teaching has offered great contributions, especially to health sciences as they allowed for many important discoveries, such as the development of new drugs and treatments, as well as the understanding of certain biological phenomena. However, activists fighting against this type of activity are still present, always emphasizing animal welfare and preventing cases of cruelty from against them. ${ }^{5,6}$

The principle of the 3Rs (Replace, Reduce, Refine) represents great progress in favor of the animals. ${ }^{30}$ In spite of that, it is necessary to think in an integrative manner, since reducing the number of animals would be pointless if the tests being carried out are of little significance, thereby invalidating the experiment as a whole. Similarly, there would be no use in reducing the number of animals without considering their suffering. This theory seeks full replacement of animal experimentation with alternative models. Nevertheless, it is still hard to imagine certain scientific research projects that involve more complex systems without using this resource., ${ }^{2,3}$

Before beginning any experiment, the researcher should be familiar with the particularities of the species, as well as thoroughly plan the research project in order to avoid unnecessary use of living animals. It is also the researcher's responsibility to provide the animals with adequate housing conditions so as to ensure their welfare and avoid any kind of pain, suffering and stress. Environmental enrichment is a way towards achieving this goal. Stress, in addition to affecting the behavior and physiology of the species, ends up interfering with the reliability of the research. ${ }^{6,8,12,13}$

The experiments must be performed in an ethical manner and be justified, in such a way so as to avoid causing pain, suffering and stress to the animals during the research. ${ }^{13}$ Whenever possible, alternative methods to using living animals should be chosen, such as in vitro testing, cadaveric studies, and computer simulations. ${ }^{2}$

\section{Conclusion}

The use of animals, both in teaching and research, still raises many controversies. Still, it cannot be denied that various substances that are essential to human health, such as medicines and vaccines, have been and will continue to be developed thanks to these experiments.

One must take into consideration the cost-benefit ratio of this type of scientific study, since animals are sentient beings and should not be used unnecessarily. Investigators are accountable for watching over the welfare of these laboratory animals, avoiding any kind of pain and suffering. Additionally, alternative methods should be used whenever possible.

Whenever necessary, either following the termination of experiments or during any of their stages, painless euthanasia of the animals is recommended, with a rapid loss of consciousness and followed by cardiorespiratory arrest and damage to the brain function. 


\section{REFERENCES}

1. Franco AL, Nogueira MNM, Sousa NGK, Frota MF, Fernandes CMSF, Serra MC. Pesquisa em animais: uma reflexão bioética. Acta Bioeth. 2014; 20(2):247-53.

2. Miziara ID, Magalhães ATM, Santos MA, Gomes EF, Oliveira RA. Research ethics in animal models. Braz J Otorhinolaryngol. 2012; 78(2):128-31.

3. Petroianu A. Aspectos éticos na pesquisa em animais. Acta Cir Bras. 1996 MES; 11(3):157-64.

4. BRASIL. Lei $n^{\circ} 11.794$ de 8 de outubro de 2008. Procedimentos para o uso científico de animais. Diário Oficial da União; 196; Seção 1.

5. Tréz TA. Caracterização do uso de animais no ensino a partir da percepção de estudantes de ciências biológicas e da saúde. Hist Cienc Saude. 2015; 22(3):863-80.

6. Singh VP, Pratap K, Sinha J, Desiraju K, Bahal D, Kukreti R. Critical evaluation of challenges and future use of animals in experimentation for biomedical research. Int J Immunopathol Pharmacol. 2016; 29(4):551-61.

7. Kehind EO. They see a rat, we seek a cure for diseases: the current status of animal experimentation in medical practice. Med Princ Pract. 2013; 22(Suppl 1):52-61.

8. Knop LB, Maria DA. Métodos substitutivos e a experimentação animal: um enfoque inovador. RESBCAL. 2016; 4(2):101-14.

9. Batalha E. Uso de animais em pesquisa abrange desafios éticos e compromisso com novas tecnologias. Radis. 2017; 174

10. Muller CA, Ramos S, Saisse AO, Almosny NRP. Videocâmeras em biotérios de experimentação: importante ferramenta no controle da contaminação ambiental na microbiota de camundongos. Arq Bras Med Vet Zootec. 2015; 67(3):689-97.

11. Weber EM, Dallaire JA, Gaskill BN, Pritchett-Corning KR, Garner JP. Aggression in group-housed laboratory mice: why can't we solve the problem? LabAnimal. 2017; 46(4):157-61.

12. Guidelines for the Use of Animals. Guidelines for the treatment of animals in behavioural research and teaching. Anim Behav. 2017; 123:1-9.

13. Neves SMP, Prates FM, Rodrigues LD, Santos RA, Fontes RS, Santana RO. Manual de cuidados e procedimentos com animais de laboratório do Biotério de Produção e Experimentação da FCF-IQ/USP. São Paulo: FCF-IQ/USP; 2013.

14. Iki Y, Ito T, Kudo K, Noda M, Kanehira M, Sueta T, et al. Animal ethics and welfare education in wet-lab training can foster residents' ethical values toward life. Exp Anim. 2017. doi: 10.1538/expanim.17-0026. [Epub ahead of print]

15. Conselho Federal de Medicina Veterinária. Guia Brasileiro de Boas Práticas para Eutanásia em Animais. Brasília: Comissão de Ética, Bioética e BemEstar Animal/CFMV; 2013.
16. Baldelli I, Massaro A, Penco S, Bassi AM, Patuzzo S, Ciliberti R. Conscientious objection to animal experimentation in Italian universities. Animals 2017; 7(24):1-8

17. Andrade GM, Lopes HDP, Felício SJO, Carmo VM, Matos EP. Experience report on teaching surgical technique without animal use. Acta Cir Bras. $2015 ; 30(5): 371-5$.

18. Joffe AR, Bara M, Anton N, Nobis N. The ethics of animal research: a survey of the public and scientists in North America. BMC Medical Ethics. 2016; 17:17.

19. Mayir B, Doğan U, Bilecik T, Yardımcı EC, Çakır T, Aslaner A, et al. Why scientists perform animal experiments, scientific or personal aim? Ulus Cerrahi Derg. 2016; 32(4):256-60.

20. Kehinde EO. They see a rat, we seek a cure for diseases: the current status of animal experimentation in medical practice. Med Princ Pract. 2013; 22(Suppl 1):52-61.

21. Bennett AJ, Ringach DL. Animal research in neuroscience: a duty to engage. Neuron. 2016; 92(3):653-7.

22. Balls M, Combes R. Animal experimentation and alternatives: revealed preferences. Altern Lab Anim. 2017; 45(1):1-3.

23. Pasupuleti MK, Molahally SS, Salwaji S. Ethical guidelines, animal profile, various animal models used in periodontal research with alternatives and future perspectives. J Indian Soc Periodontol. 2016; 20(4):360-8.

24. Zoupa M, Machera K. Zebrafish as an alternative vertebrate model for investigating developmental toxicity-The Triadimefon Example. Int J Mol Sci. $2017 ; 18(4): 817$.

25. Ramalli Jr EL, Ho W, Alves M, Rocha EM. Progress in animal experimentation ethics: a case study from a Brazilian medical school and from the international medical literature. Acta Cir Bras. 2012; 27(9):659-63.

26. Abubakar AA, Noordin MM, Azmi TI, Kaka U, Loqman MY. The use of rats and mice as animal models in ex vivo bone growth and development studies. Bone Joint Res. 2016; 5(12):610-8.

27. Brito CVB, Soares RHFC, Botelho NM. Analgesia de animais de laboratório: responsabilidade dos comitês de ética e obrigação dos pesquisadores. Rev Bioet. 2016; 24(3):528-31

28. Yang NB, Pan XJ, Cheng JJ, Lin JQ, Zhu JY. Ethical Inspection about laboratory animals. Zhongguo Ying Yong Sheng Li Xue Za Zhi. 2015; 31(6):504-7.

29. Singh VP, Pratap K, Sinha J, Desiraju K, Bahal D, Kukreti R. Critical evaluation of challenges and future use of animals in experimentation for biomedical research. Int J Immunopathol Pharmacol. 2016; 29(4):551-61.

30. Tanner R, McShane H. Replacing, reducing and refining the use of animals in tuberculosis vaccine research. ALTEX. 2017; 34(1):157-66. 